\title{
Bad girl and unmet family planning need among Sub-Saharan African adolescents: the role of sexual and reproductive health stigma
}

\author{
Kelli Stidham Hall, ${ }^{1}$ Abubakar Manu, ${ }^{2}$ Emmanuel Morhe, ${ }^{3}$ Vanessa K. Dalton, ${ }^{4}$ Sneha Challa, ${ }^{4}$ Dana Loll, ${ }^{4}$ \\ Jessica L. Dozier, ${ }^{4}$ Melissa K. Zochowski, ${ }^{4}$ Andrew Boakye, ${ }^{5}$ Lisa H. Harris ${ }^{4}$
}

${ }^{1}$ Department of Behavioral Sciences and Health Education, Rollins School of Public Health, Emory University, Atlanta, USA; ${ }^{2}$ School of Public Health, University of Ghana, Accra, Ghana; ${ }^{3}$ University of Allied Health and Sciences, Ho, Ghana; ${ }^{4}$ University of Michigan, Women's Hospital, Ann Arbor, USA; ${ }^{5}$ Komfo Anokye Teaching Hospital, Kwame Nkrumah University of Science and Technology, Kumasi, Ghana

Correspondence: Kelli Stidham Hall, Department of Behavioral Sciences and Health Education, Rollins School of Public Health, Emory University, 1518 Clifton Road, NE, GCR 560, Atlanta, GA 30322, USA.

Tel.: 404.727.8741.

E-mail: kelli.s.hall@emory.edu

Key words: Sexual and reproductive health; Stigma; Adolescents; Contraceptive use; Family planning service use; Conceptual model; Sub-Saharan Africa.

Contributions: KSH, EM, AM, VKD, RA all conceived of the project initially and designed the study methods and procedures, with additional input from LHH. MKZ, AB, SC, DL, JD led/conducted fieldwork, data collection and actively participated in analysis, with oversight from KSH, AM, EM. All authors participated in data interpretation and writing the manuscript. KSH drafted the first version of the manuscript and all coauthors provided substantial revisions and feedback, with subsequent revisions by KSH. All authors have approved the final version prior to submission. KSH confirms full access to all aspects of the research and writing process and takes final responsibility for the manuscript.

Conflict of interest: VKD is compensated as an expert witness for Bayer Pharmaceuticals in intrauterine device litigation. All other authors have no potential conflicts of interest to disclose.

Funding: this work was supported by the Society of Family Planning Research Fund Award \#SFPRF8-1, the National Institute of Child Health and Human Development (NICHD) \#1K01HD080722-01A1 (KSH), NICHD \#K12HD001438 (for $\mathrm{KSH}$ while she was at the University of Michigan, PI Johnson), and awards from the University of Michigan's African Social Research Initiative and Office of the Vice President of Research. Funding sources had no involvement in study design, in the collection, analysis, and interpretation of data, in the writing of the report or in the decision to submit the paper for publication.

Ethical approval: the study was approved by the Institutional Ethics Review Boards of the Ghana Health Services, University of Ghana, Kwame Nkrumah University of Science and Technology, and University of Michigan.

Acknowledgements: the authors would like to thank Richard Adanu MD MPH, University of Ghana School of Public Health, Accra Ghana.

Received for publication: 10 September 2017.

Revision received: 15 April 2018.

Accepted for publication: 24 April 2018.

This work is licensed under a Creative Commons Attribution NonCommercial 4.0 License (CC BY-NC 4.0).

CCopyright K. Stidham Hall et al., 2018

Licensee PAGEPress, Italy

Qualitative Research in Medicine \& Healthcare 2018; 2:55-64 doi:10.4081/qrmh.2018.7062

\begin{abstract}
Adolescent pregnancy contributes to high maternal mortality rates in Sub-Saharan Africa. We explored stigma surrounding adolescent sexual and reproductive health (SRH) and its impact on young Ghanaian women's family planning (FP) outcomes. We conducted in-depth, semi-structured interviews with 63 women ages 15-24 recruited from health facilities and schools in Accra and Kumasi, Ghana. Purposive sampling provided diversity in reproductive/relationship/socioeconomic/religious characteristics. Using both deductive and inductive approaches, our thematic analysis applied principles of grounded theory. Participants described adolescent SRH experiences as cutting across five stigma domains. First, community norms identified non-marital sex and its consequences (pregnancy, childbearing, abortion, sexually transmitted infections) as immoral, disrespectful, and disobedient, resulting in bad girl labeling. Second, enacted stigma entailed gossip, marginalization, and mistreatment from all community members, especially healthcare workers. Third, young sexually active, pregnant, and childbearing women experienced internalized stigma as disgrace, shame and shyness. Fourth, non-disclosure and secret-keeping were used to avoid/reduce stigma. Fifth, stigma resilience was achieved through social support. Collectively, SRH stigma precluded adolescents' use of FP methods and services. Our resulting conceptual model of adolescent SRH stigma can guide health service, public health, and policy efforts to address unmet FP need and de-stigmatize SRH for young women worldwide.
\end{abstract}

\section{Introduction}

Unintended pregnancy during adolescence is a persistent global public health problem and direct contributor to maternal mortality in Sub-Saharan Africa. ${ }^{1,2}$ Complex individual, sociopolitical, and health systems issues preclude widespread effective contraceptive use among young African women. ${ }^{1-4}$ In Ghana, low contraceptive use rates continue despite fairly liberal family planning (FP) laws and access to services compared to other developing countries. ${ }^{4-6}$ As much as $42 \%$ of young Ghanaian women experience an unmet need for FP even though $77 \%$ report access to modern contraception. ${ }^{4}$

While structural and systems-level barriers to adoles- 
cent contraceptive method and FP service use in Sub-Saharan Africa have been described, less is known about the role of social stigma occurring with the various dimensions of adolescent sexual and reproductive health (SRH) (i.e. sexual activity, pregnancy, childbearing, abortion, sexually transmitted infections (STIs), contraception and FP service use). . $^{3,47-19}$ Sociocultural and religious norms that frame sex and its consequences as immoral and problematic may mark or taint sexually active adolescent females within their communities, leading to subsequent shame, mistreatment and stigma. ${ }^{10-23}$ However, whether social stigma may preclude the use of FP methods and services and contribute to adverse SRH outcomes has not been well studied. Moreover, adolescent (and unmarried) women have often been neglected in FP and in stigma research, even though the consequences of stigma, unintended pregnancy, and unsafe abortion for this group can be the most severe. ${ }^{1-3}$

Stigma is a complex, contextual, dynamic process that marks an individual for an attribute that violates social expectations and is devalued culturally. ${ }^{20,21}$ Stigma, as Goffman has described, deeply discredits and transforms people from whole individuals to tainted, discounted ones. ${ }^{20}$ While over the last 50 years researchers have built upon Goffman's definition, the perception of negative characteristics and global devaluation of the possessor are two definitions of stigma typically shared across disciplines. ${ }^{20,21}$ Stigma has also been defined as labeling, stereotyping, discrimination, separation, and loss of social status, social networks, and self-esteem, that co-occur in a context in which power is exercised, and which can result in negative health and social outcomes. ${ }^{22,23}$ The stigma concept can encompass multiple statuses, identities, and characteristics at the individual level and at the structural level. 22,23

In SRH, stigma research has largely focused on HIV and AIDS. ${ }^{24-26}$ Findings from these studies have documented a profound impact of stigma on the social status, mental health, and quality of life of women living with HIV and on their utilization of HIV and antenatal health services. ${ }^{24}$ Other research has focused on stigma specifically occurring with sexual orientation ${ }^{27,28}$ and mental health conditions. ${ }^{28-30}$ Collectively, qualitative and quantitative stigma studies have resulted in some shared dimensions of the stigma concept as it may relate to health and wellbeing, two of which represent the overwhelming focus of researchers and measurement. Internalized stigma, or self-stigma, has been conceptualized as the subjective perception of being devalued and marginalized, which directly affects a person's sense of self-esteem and level of distress (Internalized stigma mental illness). ${ }^{25,26,29}$ Enacted stigma, often used interchangeably with discrimination, has been conceptualized as the negative acts that result from stigma and serve to devalue and reduce the life chances of the stigmatized). ${ }^{23,25,28}$

While these conceptualizations have been used in a few studies on abortion stigma, ${ }^{31,32}$ research to date has not formally considered stigma within a broader SRH and FP context. Nor have studies formally investigated a more comprehensive set of dimensions comprising stigma, beyond enacted and internalized stigma, that may relate to young peoples' SRH perceptions and experiences, especially in sociocultural contexts like Ghana. In our own prior qualitative analysis of data from this same cohort of young Ghanaian women, ${ }^{33}$ participants alluded to lived experiences which we believe support a need for a more nuanced understanding of stigma as a potentially unique phenomenon. Taking a broad and initial perspective using a grounded theory approach, we previously found that influences operating at the community and macro levels of young women's environments, including unaccepting social, cultural and religious norms around premarital sexual activity, pregnancy, and abortion, shaped FP decisionmaking and behaviors. ${ }^{33}$

Thus, building upon that work, we further explore the sociocultural context of adolescent SRH in Ghana, specifically and more comprehensively considering the potential of SRH stigma and its impact on young women's contraceptive method and FP service use.

\section{Methods}

We conducted in-depth, semi-structured interviews with 63 women ages 15-24 years in Accra and Kumasi, Ghana. We used a community-based cluster sampling technique to select five Ghana Health Service (GHS) facilities and five Senior High Schools within the Ghana Educational Service (GES) across large, culturally-diverse sub-metro regions in each major city. This sampling frame provided heterogeneity in types of clinics (antenatal, postnatal, FP, adolescent, abortion, child welfare) and schools (public, co-education, female only) and the populations they serve (i.e. reproductive, relationship, socioeconomic, religious characteristics). The study was approved by the Institutional Ethics Review Boards of the GHS, University of Ghana, Kwame Nkrumah University of Science and Technology, and University of Michigan. We obtained parental consent waivers from all Ghanaian IRBs given the sensitive nature of our survey and to ensure confidentiality.

Eight Ghanaian research assistants (RAs), who were trained by our Ghanaian PIs and Ghanaian and U.S. research program managers, approached women at recruitment sites, provided study information, invitations to participate, and obtained informed consent. We offered a modest gift (telephone card \$7 cedis) as compensation for our participants times - an amount that was recommended to be appropriate and non-coercive by our well-established Ghanaian research team and approved by our Ghanaian and U.S. Institutional Review Boards. RAs conducted interviews in private offices using semi-structured interview guides. Guides were informed by a comprehensive literature review on stigma and its measurement and key known domains (i.e. enacted and internalized stigma) 
described above, relevant codes and themes from our prior modified grounded-theory guided qualitative analysis (e.g. social norms) and related studies on the social context of adolescent SRH. ${ }^{33-35}$ This all provided a foundational framework to organize our more focused, indepth analysis and findings and account for new domains and dimensions of stigma that emerged here.

Interviewers elicited information about sociodemographics, health, reproductive, and contraceptive histories, SRH knowledge/attitudes, and perceived community norms/experiences with sex, pregnancy, childbearing, abortion, STIs, contraception, and FP services. We probed for perceptions and experiences (participant's own and/or of women in their communities) related to: i) circumstances/decision-making around sexual initiation and/or pregnancy; ii) health and social consequences; iii) changes in life goals; iv) healthcare. Topics moved from less to more sensitive to enhance rapport and validity. Guides were pre-tested in the field to assure clarity and comprehension. Interviews, ranging from 20 to $90 \mathrm{~min}$ utes (depending upon level of sexual experience), were conducted in English or local languages (Twi, Ga), digitally recorded, transcribed verbatim, and translated by Ghanaian team members when needed.

Our thematic analysis used an inductive, modified grounded theory approach. ${ }^{36,37}$ Strauss and Corbin define grounded theory as a methodology for developing theory that is grounded in data systematically gathered and analyzed..$^{37}$ Theory may evolve initially during the research process and also, if existing theories seem appropriate to the area of investigation, then these may be elaborated and modified as incoming data further inform them. ${ }^{37}$ In our case, our analysis was theory generating but was also informed by preexisting themes and codes from our initial qualitative analysis, the broader literature on the social context of adolescent SRH literature, pre-established stigma domains the stigma literature review, and healthrelated stigma conceptualizations. New codes that arose from participants' language and discourse which emerged here were used to inform and refine a new working model of adolescent SRH stigma.

Initially, two Ghanaian research assistants in each city working to collect data in the field met regularly with our study principal investigators (PI) (in person with Ghanaian PIs and via Skype with U.S. PI) and our Ghanaian and U.S. program managers to translate and then review a subset of early collected transcripts, discuss potential emerging codes, and revise semi-structured interview questions as needed on an ongoing basis throughout the study, for a constant comparative approach. Once data collection was complete, two or more team members then independently reviewed all transcripts together. We held weekly team meetings to review selected transcripts together, decide upon final codes and code definitions, and identify themes and sub-themes. Through an iterative process, we developed and refined a formal codebook. Two members then coded all transcripts. Weekly meetings enabled the team to resolve discrepancies and discuss bias and selectivity. Regular conversations between U.S. and Ghanaian team members throughout all phases of data collection and analysis provided opportunities to address reflexivity, share preconceptions, consider competing conclusions, and establish metapositions. Data were managed and analyzed using Dedoose, a web-based qualitative data software package that we chose for this project given its high level of security, easy access, user friendliness, and ease of collaboration.

\section{Results}

Table 1 presents sample characteristics of the 63 adolescent and young adult Ghanaian female participants in our study. Findings about participants' perceptions and experiences related to adolescent SRH stigma, which were similar across the continuum of SRH experiences and emerged as what we interpret in terms of five distinct but interrelated stigma domains or themes (Table 2), are presented below.

\section{Community norms}

Overwhelmingly, participants discussed unsupportive, unaccepting and negative community attitudes toward all dimensions of adolescent SRH - sexual activity first and foremost, but also its consequences (pregnancy, childbearing, abortion, STIs, contraception and FP service use). SRH experiences, especially outside of marriage, were considered immoral, disobedient, disrespectful, and in direct conflict with religious teachings (premarital sex was considered immoral) and established norms for acceptable adolescent and female behavior. A 16-year-old student from Kumasi commented,

Doctrines state sex is really bad at this stage... from the bible, when you are not married, it is not advisable. You will spoil yourself, easily get pregnant, sexually transmitted diseases, and illnesses.

Some participants even believed that adolescent sexual activity and pregnancy were illegal behavior.

Some said it was not at a good time (to get pregnant as an adolescent). Others too said although the pregnancy is at a bad time, I cannot abort it. So I gave birth. They said pregnancy at the age of 19 years is not good. Some too said it was written in constitution that, for a woman to get pregnant, she has to be 18 years and over. So if at the age of 19 I am going to give birth, it is okay. But people talked a lot about the time I got pregnant and they had different opinions. But they later accepted the pregnancy (Previously pregnant young adult family planning clinic patient in Accra).

Additionally, adolescents were believed to be of $a$ tender age, lacking readiness and maturity for sex and its consequences, and unable to manage the emotional, fi- 
nancial, and social responsibilities required. Readiness was also described as educational attainment, and sex was a competing activity. Sex and pregnancy could result in forfeiture of students' goals. One participant's comments illustrated this idea.

When you are coming up and you don't want to be involved in sex or immoral acts, then you have to concentrate on your education. Or when your parents tell you to do something for them, you have to focus on what you have been told to do. If you want to (have sex), you can do it after (you finish school) (22-yearold previously pregnant FP clinic patient in Accra).

The most consistent, vivid description of community norms around adolescent SRH was through stories of bad girl. This language, used by nearly all participants, referred to labeling of adolescents with sex, pregnancy, childbearing, abortion, and FP experiences as bad, spoiled and tainted. Bad girl could also extend to families and communities, leading to tarnished homes and schools. Bad girls were felt to result from failed parents and leaders, as one participant said,

They say her parents are bad, not teaching her the right thing. Teachers and religious leaders are also not doing their part. That's why she is giving birth at the wrong age. Also, she's a bad girl (15-year-old high school student in Accra).

Another 16-year-old high school student in Accra stated,

They see (an adolescent who engages in sex) as a bad child, a child who disrespect his/her parents and don't listen to their advice. Because almost all the people in the community advise their children not to get involved in such activity, but children who have bad peers just follow their friends and indulge themselves in such acts. So they see that as bad behavior.

The bad girl image could extend to families and communities, leading to tarnished homes and schools. It also carried health (physical, mental) and social (e.g. disrupted education, employment, relationships, living situations) consequences, which were especially dire for those whose recourse was abortion which could bring a curse upon bad girls, leading to infertility and misfortune.

An adolescent who becomes pregnant and has an abortion wouldn't really get a proper marriage because when you are about to marry people talk and some men also try to investigate. So people will say this lady has had an abortion even if it's once they will say thrice, and you will not be socially accepted in the community (16-year-old high school student in Kumasi).

However, in some instances described by participants, sex, childbearing or abortion was tolerated. Community norms at times recognized that some young women face extreme circumstances in which sex may be permissible.

Some of the people see it to be normal (to have sex during adolescence) and others always look down upon them. In a situation where by they have sex to bring money home, in that house she will be hailed.
Table 1. Characteristics of the sample.

\begin{tabular}{|c|c|c|}
\hline$(\mathrm{N}=63)$ & $\mathbf{n}$ & $\%$ \\
\hline \multicolumn{3}{|c|}{ Sociodemographics } \\
\hline \multicolumn{3}{|l|}{ Age in years } \\
\hline $\begin{array}{l}15 \\
16 \\
17 \\
18 \\
19 \\
20 \\
21 \\
22 \\
23 \\
24\end{array}$ & $\begin{array}{c}5 \\
10 \\
12 \\
6 \\
9 \\
5 \\
7 \\
4 \\
1 \\
3\end{array}$ & $\begin{array}{c}8 \% \\
16 \% \\
19 \% \\
10 \% \\
14 \% \\
8 \% \\
11 \% \\
6 \% \\
2 \% \\
5 \%\end{array}$ \\
\hline \multicolumn{3}{|l|}{ Highest level of education attained } \\
\hline $\begin{array}{l}\text { Primary/None } \\
\text { Middle/Junior High School } \\
\text { Secondary/High School }\end{array}$ & $\begin{array}{c}7 \\
21 \\
28\end{array}$ & $\begin{array}{l}11 \% \\
33 \% \\
44 \%\end{array}$ \\
\hline \multicolumn{3}{|l|}{ Employment status } \\
\hline $\begin{array}{l}\text { Employed } \\
\text { Unemployed } \\
\text { Student }\end{array}$ & $\begin{array}{l}13 \\
22 \\
28\end{array}$ & $\begin{array}{l}20 \% \\
35 \% \\
44 \%\end{array}$ \\
\hline \multicolumn{3}{|l|}{ Marital status } \\
\hline $\begin{array}{l}\text { Married } \\
\text { Not married }\end{array}$ & $\begin{array}{c}7 \\
51\end{array}$ & $\begin{array}{l}11 \% \\
81 \%\end{array}$ \\
\hline \multicolumn{3}{|l|}{ Preferred language } \\
\hline $\begin{array}{l}\text { English } \\
\text { Twi }\end{array}$ & $\begin{array}{l}30 \\
31\end{array}$ & $\begin{array}{l}48 \% \\
49 \%\end{array}$ \\
\hline \multicolumn{3}{|l|}{ Religious affiliation } \\
\hline $\begin{array}{l}\text { Catholic } \\
\text { Muslim } \\
\text { Protestant } \\
\text { Pentecostal/Charismatics } \\
\text { Other }\end{array}$ & $\begin{array}{c}3 \\
7 \\
13 \\
34 \\
4\end{array}$ & $\begin{array}{c}5 \% \\
11 \% \\
21 \% \\
54 \% \\
7 \%\end{array}$ \\
\hline \multicolumn{3}{|l|}{ Recruitment site } \\
\hline $\begin{array}{l}\text { Accra, Ghana } \\
\text { Senior High School } \\
\text { Antenatal/Postnatal Clinic } \\
\text { Family Planning/Adolescent Clinic } \\
\text { Kumasi, Ghana } \\
\text { Senior High school } \\
\text { Antenatal/Postnatal Clinic } \\
\text { Family Planning/Adolescent Clinic }\end{array}$ & $\begin{array}{c}31 \\
12 \\
12 \\
7 \\
32 \\
16 \\
10 \\
6\end{array}$ & $\begin{array}{c}49 \% \\
20 \% \\
20 \% \\
9 \% \\
51 \% \\
26 \% \\
16 \% \\
9 \%\end{array}$ \\
\hline
\end{tabular}

Reproductive History

\begin{tabular}{lcc}
\hline Number of prior pregnancies & & \\
\hline 0 & 28 & $44 \%$ \\
1 & 16 & $25 \%$ \\
2 & 12 & $19 \%$ \\
3 & 6 & $10 \%$ \\
\hline
\end{tabular}

\begin{tabular}{lcc}
\hline Age at first pregnancy & & \\
\hline 15 & 1 & $2 \%$ \\
16 & 5 & $8 \%$ \\
17 & 5 & $8 \%$ \\
18 & 6 & $10 \%$ \\
19 & 1 & $2 \%$ \\
20 & 3 & $5 \%$ \\
21 & 4 & $6 \%$ \\
N/A & 28 & $44 \%$ \\
\hline
\end{tabular}

\begin{tabular}{lcc}
\hline Number of live births & & \\
\hline 0 & 12 & $19 \%$ \\
1 & 17 & $27 \%$ \\
2 & 4 & $6 \%$ \\
3 & 1 & $2 \%$ \\
N/A & 28 & $44 \%$ \\
\hline
\end{tabular}

Results are presented as frequencies and proportions. Numbers may not add to $100 \%$ due to $0-10 \%$ missing data across some indicators. 
Others who do it maybe for pleasure hide it. So in the community it varies because those who do those things, some see them as important people and others also see them as bad people (16-year-old high school student in Kumasi).

Also, for adolescents with limited upward mobility, pregnancy and motherhood could provide respect and admiration. For adolescents in school and considered on track, abortion was quietly understood to preserve education and employment goals, maintain SRH secrets, and avoid long-term stigma.

People will treat the person who is pregnant better than the one who had an abortion but after some time to come the news about the one who had abortion will die down and people will even forget about it and the person will begin to live that normal life again. But (not for) the person who had the child. Since the child is there people will always remember that you had a child at a younger age (17-year-old high school student in Accra).

Nonetheless, publically abortion was overwhelmingly unacceptable, even a double sin - that getting pregnant in the first place is a problem of its own.

Finally, participants commented on the evolution of norms and attitudes about SRH over time in their communities and intergenerational differences in acceptability of adolescent pregnancy and childbearing.

I think people don't frown much because it's like the order of the day. Many young ones are getting pregnant every now and then, so is normal nowadays. Yeah, (the stigma) has gone down because now teenagers get pregnant often so it's normal with them (16-year-old high school student in Kumasi).

\section{Enacted stigma}

Gossip, marginalization, discrimination, and mistreatment were forms of enacted stigma confronted by adolescents with SRH experiences. Fear of contagion - that SRH taint could infect others who become spoiled toowas a major underlying source.
If you are walking with your pregnant friend, best of the same feathers flock together. People will say you will be the next to get pregnant...no one will want to walk with her again (16-year-old student, Kumasi).

Similarly, another 18-year-old high school student in Accra participant said,

(The community) sees (adolescents who become pregnant and have an abortion) as bad people because aborting a child is like killing a person. Oh they don't talk about them in a good manner and don't treat them in a good way because they know they are spoilt. So they don't allow their (own) children to get closer to them because they will spoil their children too.

Gossip, the most common form of enacted stigma, traveled quickly in communities, and while church members were a common source, peer gossip was often the most troubling. This was described by a 16 -year-old student from Kumasi,

She is mocked if she is not married, especially a teenager. She will be shy to come out, staying indoors because (her peers) will gossip and look at her...insult and laugh at her. Things will change because no one wants to walk with a bad girl.

Sexually active and pregnant adolescents were routinely rejected by loved ones, expelled from schools, homes, and churches, and subsequently suffered loneliness, sadness, and depression. Verbal, psychological, and physical mistreatment, including being shouted and screamed at and even beaten, could be perpetrated by any member of adolescents' social networks (though most often parents), and contributed to further public humiliation and disgrace.

One participant commented on parents and teachers as perpetrators of enacted stigma.

The mother will consider (the young women who becomes pregnant) but the dad, I don't think so. Sometimes she is likely be thrown out of the house and other family members might do same but it all depends on the relationship she has with them. When she is very close to them, like the aunties, they might welcome her

Table 2. Domains of stigma.

\begin{tabular}{llll}
\hline & Stigma domain & Description & $\begin{array}{l}\text { Example related to adolescent sexual and reproductive } \\
\text { health }\end{array}$ \\
\hline 1. & Community norms & Others' perspectives of the stigmatized attribute & $\begin{array}{l}\text { Community norms about adolescents having sex or using } \\
\text { modern contraception }\end{array}$ \\
\hline 2. & Enacted stigma & $\begin{array}{l}\text { Social and interpersonal experiences related to having } \\
\text { the stigmatized attribute }\end{array}$ & $\begin{array}{l}\text { Experiencing discrimination, marginalization, or violence } \\
\text { from family after having an abortion }\end{array}$ \\
\hline 3. & Internalized stigma & $\begin{array}{l}\text { One's own perceptions of stigmatized attribute, } \\
\text { based upon social values }\end{array}$ & $\begin{array}{l}\text { Feeling shamed or blamed for becoming pregnant as an } \\
\text { adolescent }\end{array}$ \\
\hline 4. & Non-disclosure & $\begin{array}{l}\text { Worries, consequences, and actions related to disclosing } \\
\text { the stigmatized attribute }\end{array}$ & $\begin{array}{l}\text { Adolescents' fear of seeking family planning services because } \\
\text { providers and family will know about sexual activity }\end{array}$ \\
\hline 5. & $\begin{array}{l}\text { Stigma resilience } \\
\text { and management }\end{array}$ & $\begin{array}{l}\text { Qualities or actions used to overcome /manage stigmatized } \\
\text { attribute; positive aspects of the stigmatized attribute }\end{array}$ & $\begin{array}{l}\text { Personal strategies, support and resources used to cope with } \\
\text { early childbearing or prevent pregnancy }\end{array}$ \\
\hline
\end{tabular}


but others will shun her. The (teachers) will sack her and be using her as an example to advise others, and she won't be happy herself (16-year-old high school student in Kumasi).

Another commented on the humiliation faced by religious leaders.

Church members treated me well but the pastor really laughed at me and even used me in his preaching, later asking me to stand in front of the whole congregation. I was shy when he called me forward (23-yearold FP clinic patient in Kumasi with prior adolescent pregnancy experience).

In some circumstances, enacted stigma experiences could differ according to pregnancy resolution. One participant commented on this regarding birth versus abortion.

They rain insult on (adolescents who become pregnant), point fingers at them and people often do not welcome them when they get close to them. But they will treat the teenagers who give birth at a tender age better than the woman who had abortion because society frowns at women who do abortion (16-year-old high school student in Kumasi).

\section{Internalized stigma}

Internalized stigma followed enacted stigma and resulted from negative community norms around adolescent SRH. Adolescent sexual activity and pregnancy brought feelings of disgrace, shame, embarrassment, and feelings about oneself as bad or spoiled. One participant described this.

They will treat (young women who become sexually active and pregnant) in a bad manner...because you've brought disgrace to your family and to your teachers... because they have taught you or educated you on those things, so they weren't expecting you to go into (sexual activity). So it's a big disgrace to the teachers, and the family, and to the whole community (17-year -old nulliparous, unmarried high school student in Accra).

The collection of self-loathing feelings that accompanied sex, pregnancy, and abortion was consistently referred to as shy. Shyness seemed to have a connotation extending beyond its western interpretation of bashful or timid. One 22-year-old, married, FP clinic patient in Accra described the complexity,

(My pregnancy) became a shame to me, but at a point I ignored it. I had already aborted one pregnancy. Aborting a second is not good. When I gave birth fresh, I felt shy. In my community, girls of fifteen years give birth and are okay. I gave birth at nineteen, yet I say it is a shame.

\section{Non-disclosure}

Non-disclosure and secret-keeping were strategies used to avoid or reduce enacted and internalized stigma, at least temporarily. Fear of reactions motivated decisions not to disclose sex or pregnancy and was in direct conflict with adolescents' willingness to seek FP care. Seclusion (often forced by family) kept pregnancies hidden from the community. In other cases, abortion kept both sex and pregnancy a secret.

If she does the abortion, she will be going through pain but nobody knows. But if the young girl is pregnant and schooling, she cannot walk in town. People will gossip. She will hide, but when they see her, they will insult her (19-year-old student, Accra).

Similarly, another young adult antenatal clinic patient in Kumasi said,

Normally they do not second us in aborting pregnancy but mothers especially do not want to be disgraced, they tell their child to abort. Society will not tell you to abort because they know biblically it's not right to do abortion.

\section{Stigma resilience and management}

Resilience to stigma was seldom described by participants. Various forms (emotional, financial, physical) and sources (family, partners, teachers) of social support helped women manage stigma, but mothers' support was especially critical during pregnancy and childbearing. One participant described this.

She gets support from her parents. They provide her with the things she needs and what the child will also need. The mother has to take an important role when the child has been born, teaching the girl how to breastfeed, bath the baby, and do certain things... support the child (15-year-old high school student in Kumasi).

Stigma was reduced if the partner married the woman and provided for the child. However, adolescents without any one to care for her and her child are left wandering. One 17-year-old student in Kumasi commented on community support when discussing her pregnant friend who was abused by her family.

Other people didn't treat her badly. They received her because they felt the pain she was in ... a young girl, pregnant, beaten, sleeping outside. They felt for her...tried to help her.

Some young women managed stigma through the hope that negative experiences associated with SRH were temporary and would ultimately have little impact on her long-term life circumstances and goals. A pregnant adolescent antenatal clinic patient in Kumasi described this.

Sometimes, I feel bad when I see a friend who's schooling and I'm pregnant...locked. Anyway, it's not forever. I will come out soon. I will also go to school.

Education, employment, or relationships opportunities could be resumed, and reputations could be salvaged, through marrying the partner or successfully providing for the child, which as noted above could bring responsibility and respect.

It was like, if I give birth, people will say, 'Why 
didn't you wait for the man to marry you before?' 'Why didn't you allow the man to come and meet your parents before walking with him.' At times too, when you meet a man and he goes to perform the marital rites, his parents will say they want a grandchild but you might not be ready to have a child yet. But if you give birth before and you go and marry the man, it is good, because there are some women who after one or two years into marriage do not have any children. Initially, when I was pregnant, I thought after giving birth the man will not do anything for me. But after giving birth, he did something for me (married me) (21-year-old married family planning clinic patient in Accra with 2 prior pregnancies and one child).

\section{Impact of stigma on family planning}

Overall, participants described stigma experiences as adversely impacting adolescents' access to and utilization of FP methods and services. Contraception was rarely mentioned as a strategy to avoid pregnancy. Rather, young women kept FP a secret, carrying the burden alone, as one participant said, It's my personal life... if I feel like going for family planning, it is my problem. Unaccepting community norms around adolescent SRH issues negatively impacted opportunities for adolescents' reception of SRH counseling, as one participant noted,

If you advise (the young people about sex) they will insult you. If you talk about it, they will langh at you and some may hiss at you. They will insult you because they don't care. (21-year -old antenatal clinic patient in Accra with 2 prior pregnancies).

The act sex and disclosure of it, which was frowned upon, precluded use of contraceptive methods among sexually active adolescents, even when contraception was recognized as a potentially responsible thing to do as cited by a 17 -year-old high school student in Accra,

Well, the community would see it as good and at the same time bad (to use contraception). Because on the safer side, she is trying to prevent the pregnancy, which she doesn't want to give birth at a tender age. And it's bad because it's bad for me to go and have sex.

Reluctance to disclose SRH issues, feelings of shyness, and fear of judgment and mistreatment from healthcare workers were explicitly noted as precluding SRH service use. When asked about adolescents in need of FP care, a 17-year-old high school student from Accra noted,

Nurses will send her away, say she is a bad girl, and insult pregnant teenagers. No, she can't go get family planning.

Similarly, another 17-year-old high school student from Accra said,

No, teenagers don't patronize health services because they feel shy and are not of age to give birth or get pregnant, so they will definitely feel shy to go.

Discrimination from healthcare workers, especially nurses, was commonly described.
Adolescents seeking services were told they are prostitutes, animal-like, and below the standard of normal people. One participant described this experience.

I once escorted (my pregnant friend) to the hospital and it was like the (staff) including the nurses, everyone was like insulting her and even the doctors didn't give her the best of treatment because she is young. So, she is reluctant to go to the hospital again (16-year-old high school student in Kumasi.

Poor treatment was not always universal, though; sometimes persistent adolescents in need of care could find trustworthy, compassionate staff who would take them in. An unmarried 21-year-old from a Kumasi antenatal clinic with three prior pregnancies said,

I used to go to the hospital...one day, a nurse stared and said, 'Are you pregnant at this age? When we advise you, you don't listen. 'The nurses would not take my card. Ifelt ashamed, vowing never to go there again. I went to (another hospital). The midwife welcomed me well.

Finally, stigma left adolescents without other trusted resources or safe spaces to turn for SRH counseling, as one 17-year-old pregnant Kumasi antenatal clinic patient said, My mother will say you are a bad, stubborn girl, insulting you for asking those questions.

\section{Discussion}

Stigma stories of these young women spanned different dimensions of SRH and multiple stigma domains. Terminology used was overwhelmingly negative, culminating with bad girl. This gendered norm was a salient underpinning of our interviews and was consistent with a gendered organization of life. Expectations of marriage left young unmarried women alone to carry the burdens of unintended pregnancy risk, negotiating FP, obtaining healthcare, securing marriage, pregnancy decision-making, and early motherhood responsibilities. Not dissimilar from HIV, infectious disease and mental illness stigma, ${ }^{20-30}$ adolescent SRH stigma was grounded in deeprouted fears of contagion, of becoming spoiled and tainted too, which fueled social marginalization and discrimination. The lived experiences with internalized and enacted stigma described by these young women in the context of SRH and their communities were results consistent with conceptualizations noted in the literature on HIV/AIDs and mental health stigma. ${ }^{20-30}$ Other domains of stigma that emerged as specific codes and themes here formalize the roles of community norms and disclosure within stigma, features that have been described as contextual dimensions of stigma in the broader literature, though not as predominant domains. ${ }^{25}$

In the case of $\mathrm{SRH}$, these young women struggled to balance and weigh multiple stigma identities - most of which had similar features but some of which were unique - related to different SRH experiences. Some described 
abortion stigma as compounding sex and pregnancy stigmas, while others described it as preventing childbearing stigma. Regardless, the stigma process and its consequences (e.g. lost educational opportunities, violence, mental health symptoms) were similar for different SRH experiences, not easy to bear, and further stigmatizing. While stigma resilience was seldom discussed, social support helped adolescents to manage stigma and survive early pregnancy and childbearing. Related work specifically on adolescent pregnancy and discrimination supports these findings. ${ }^{11-13,18,34,35}$

Our findings contribute to a richer understanding of stigma as a process and a fuller conceptualization of its various dimensions specifically related to adolescent SRH and as it shapes young women's FP outcomes. Building upon theories accounting for enacted and internalized stigma, our new resulting working hypothesis and conceptual model (Figure 1) depicts how community norms (determined by lay/professional attitudes, gender/cultural norms, religion) influence the extent to which young women experience enacted and internalized stigma. Stigma may be facilitated by nondisclosure of SRH and/or reduced by stigma resilience/management. This process impacts adolescents' access to and use of FP methods and services, resulting in met or unmet need. The model accounts for the dynamic interplay between different, competing stigma domains, the balance between protective factors (e.g. family support) and risk factors (e.g. exposure to healthcare discrimination), and evolving social environments (e.g. changing gender norms or provider practices may reduce stigma, regardless of low social support).

\section{Conclusions}

It is noteworthy that our findings and resulting conceptual model represent a fairly westernized notion of stigma and several of our investigative team leaders are U.S-based researchers and were intervening in a different cultural and social context in Ghana. Thus, there was a potential for threat of researchers voices to be present or focal in data interpretation, analysis and in presentation of results and our western perspective in designing and implementing this study could have biased the data collection and analysis processes. Additionally, stigma is a construct which has been relatively understudied in SubSaharan Africa and other developing contexts, and health professionals and researchers may label complex sociocultural phenomena as stigma when stigma may not fully capture or accurately represent real people in real life situations. Indeed, the lens through which we approached this research question and study design could have potentially shaped participants' disclosure of their lived experiences within their communities related to SRH norms, attitudes, and behaviors. As previously noted, however, we emphasize findings here which we felt represented stigma specifically, but our broader research efforts published elsewhere contextualize stigma in a much broader social environment and multi-level framework to understand the determinants of adolescent SRH..$^{33}$ Nonetheless, it remains unclear whether these stigma findings fit perfectly in accord with complex community norms and rituals true to these Ghanaian young women.

Several other potential limitations are noteworthy. First, participants in this study were not a representative sample of all young women in Ghana or elsewhere and thus results are not generalizable to other countries and settings where SRH stigma experiences may have been different. Second, response and social desirability bias on part of participants may have also been a concern given our focus on sensitive issues, including sex and abortion. Third, our use of incentives as compensation for our participants time could be viewed as coercing participation in this low-resource set-
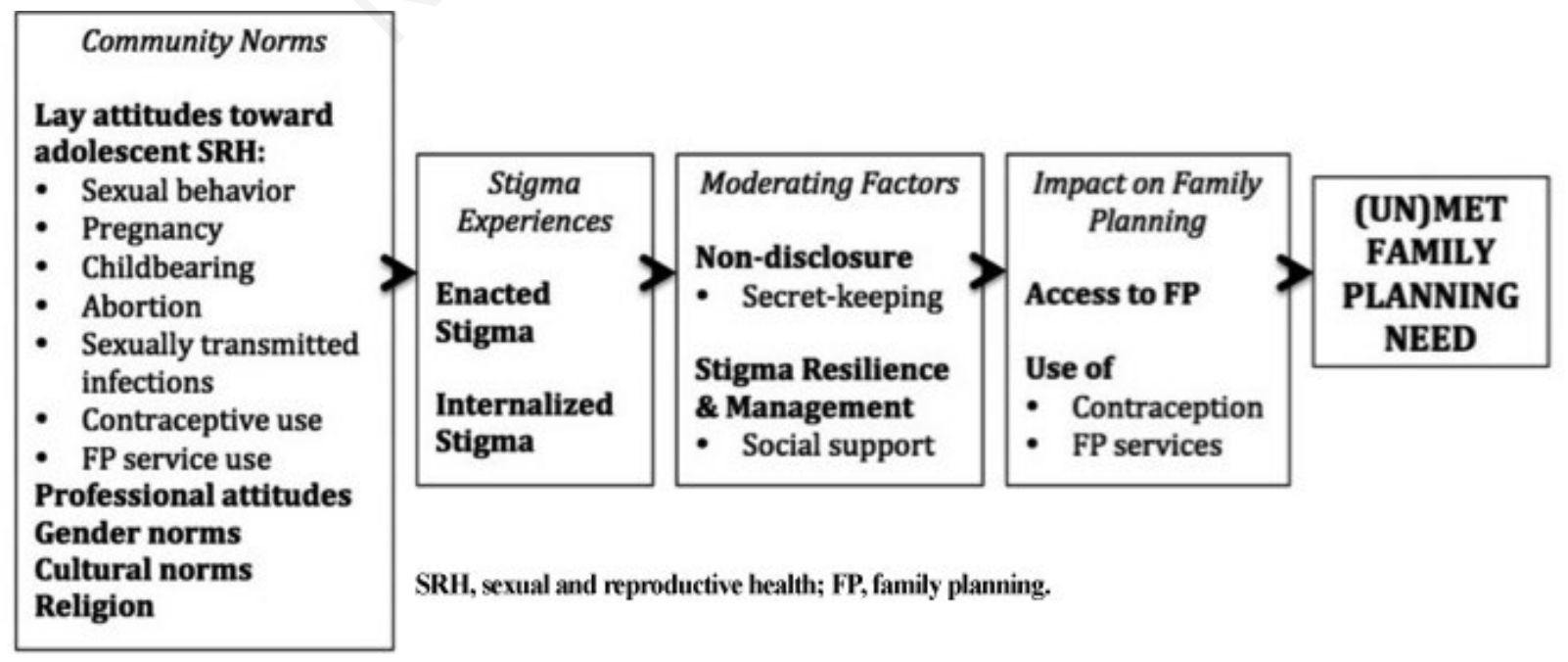

SRH, sexual and reproductive health; FP, family planning.

Figure 1. Adolescent sexual and reproductive health stigma and its impact on family planning need. 
ting, although our incentives were modest and recommended by our in-country team who is well versed with ethical research practices in this context. To address these potential biases, we rigorously trained and had regular debriefings with research assistants and study investigators on appropriate interview procedures, including ensuring comprehension and clarity of questions, establishing rapport, and probing for sensitive information. ${ }^{36}$

Despite these limitations, the adolescent SRH stigma model can guide future studies to quantify the impact of stigma on FP outcomes (the focus of our ongoing work), as well as inform multi-dimensional strategies to shift sociocultural paradigms of adolescent SRH and address young women's unmet FP needs. Future research efforts and subsequent clinical practice, policy, and advocacy strategize can: i) evaluate stigma reduction/management interventions that address the multiple domains of stigma in healthcare and community-based settings; ii) provide and evaluate improved access to adolescent-friendly, patient-centered, holistic services and its impact on stigma and SRH outcomes; iii) identify strategies to reduce systems-level barriers to contraceptive methods and SRH counseling; iv) incorporate sociocultural context and stigma reduction/management content into universal, comprehensive sex education programs; v) implement messaging strategies at the social and cultural levels to promote societal openness and comfort regarding adolescents as sexual beings as a health promotive strategy. ${ }^{3,8-}$ 10,14,15 Further research studies are needed to understand the impact of intersecting stigmas (e.g. of reproduction, mental health, poverty, minority, HIV), understudied stigmas (e.g. transactional sex), and stigma resilience on health outcomes. ${ }^{22}$ Finally, health care professionals, researchers, and policy-makers must embrace a broader framework of sexual and reproductive health promotion in order to improve family planning outcomes and the overall health and wellbeing of young women in Sub-Saharan Africa and beyond..$^{8-10}$

\section{References}

1. Singh S, Sedgh G, Hussain R. Unintended pregnancy: Worldwide levels, trends and outcomes. Stud Fam Plann 2010;41:241-50.

2. Tsui AO, McDonald-Mosley R, Burke AE. Family planning and the burden of unintended pregnancies. Epidemiol Rev 2010;32:152-74.

3. Hindin MJ, Christiansen CS, Ferguson BJ. Setting research priorities for adolescent sexual and reproductive health in low-and middle-income countries. Bull WHO 2013;91:10-8.

4. Machiyama K, Cleland J. Insights into unmet need in Ghana. Step up research report. London, UK: London School of Hygiene \& Tropical Medicine; 2013.

5. Adanu R, Seffah J, Anarfi JK, et al. Sexual and reproductive health in Accra, Ghana. Ghana Med J 2012;46:58-65.

6. Asamoah BO, Agardh A, Ostergen P. Inequality in fertility rate and modern contraceptive use among Ghanaian women from 1988-2008: Int J Equity Health 2013;12:1-12.

7. Kelly DM. Stigma stories: four discourses about teen mothers, welfare, and poverty. Youth Soc 1996;27:421-49.

8. Fenton KA. Time for change: Rethinking and reframing sexual health in the United States. J Sex Med 2010;9:250-2.

9. Sanfilippo JS. Teen pregnancy prevention: sexuality the magic bullets. J Pediatr Adolesc Gynecol 2015;28:207-8.

10. Satcher D, Hook EW, Coleman E. Sexual health in America: Improving patient care and public health. JAMA 2015;314: 765-6.

11. Levandowski BA, Kalilani-Phiri L, Kachale F, et al. Investigating social consequences of unwanted pregnancy and unsafe abortion in Malawi: the role of stigma. Int J Gynecol Obstet 2012;118:167-71.

12. Atuyambe L, Mirembe F, Johansson A, et al. Experiences of pregnant adolescents-voices from Wakiso District, Uganda. Afr Health Sci 2005;5:304-9.

13. Wienmann CM, Rickert VI, Berenson AB, Volk RJ. Are pregnant adolescents stigmatized by pregnancy? J Adolesc Health 2005;36:1-7.

14. Glinski A, Sexton M, Petroni S. Understanding the adolescent family planning evidence base. International Center for Research on Women. Available from: http://www.icrw.org/ publications/understanding-adolescent-family-planning-evidence-base-review-literature. Accessed: August 2015.

15. Langer A, Meleis A, Knaul FM, et al. Women and health: the key for sustainable development. Lancet 2015;386:1165-210.

16. Hokororo A, Kihunrwa AF, Kalluvya S, et al. Barriers to access reproductive health care for pregnant adolescent girls: A qualitative study in Tanzania. Acta Paediatr 2015;104: 1291-7.

17. Lince-Deroche N, Hargey A, Holt K, Shochet T. Accessing sexual and reproductive health information and services: A mixed methods study of young women's needs and experiences in Soweto, South Africa. Afr J Reprod Health 2015; 19:73-81.

18. Hall KS, Kusunoki Y, Gatny H, Barber J. Social discrimination, mental health, and risk of unintended pregnancy among young women. J Adolesc Health 2015;56:330-7.

19. Thorburn S, Bogart LM. African American women and family planning services: perceptions of discrimination. Women Health 2005;42:23-39.

20. Goffman E. Stigma: Notes on the management of spoiled identity. New York, NY: Prentice Hall; 1963.

21. Norris A, Bessett D, Steinberg JR, et al. Abortion Stigma: A reconceptualization of constituents, causes, and consequences. Womens Health Issues 2011;21:549-54.

22. Hatzenbuehler ML, Phelan JC, Link BG. Stigma as fundamental cause of population health inequalities. Am J Pub Health 2013;103:813-21.

23. Link BG, Yang LH, Phelan JC, Collins PY. Measuring mental illness stigma. Schizophr Bull 2004;30:511-41.

24. Turan JM, Hatcher AH, Medema-Winjnveen J, et al. The role of HIV-related stigma in utilization of skilled childbirth services in rural Kenya: a prospective mixed-methods study. PLOS Med 2012;9:1-12.

25. Nyblade L, MacQuarrie K. Can we measure HIV/AIDS stigma and discrimination? Current knowledge about quantifying stigma in developing countries. Washington, DC: ICRW, USAID; 2006.

26. Ginindza T. Measuring AIDS stigmas in people living with HIV/AIDS: The internalized AIDS-related stigma scale. AIDS Care 2009;21:87-93. 
27. Garnets L, Herek GM, Levy B. Violence and victimization of lesbians and gay men: mental health consequences. In: Kimmel DC, Garnets L, eds. Psychological perspectives on lesbian, gay, and bisexual experiences. New York, NY: Columbia University Press; 2003.

28. Van Brakel WH. Measuring health-related stigma: A literature review. Psychol Health Med 2006;11:307-34.

29. Kalichman SC, Simbayi LC, Cloete A, et al. Internalized stigma of mental illness: Psychometric properties of a new measure. Psychiatr Res 2003;121:31-49.

30. Sartorius N. Iatrogenic stigma of mental illness. BMJ 2002; 324:1470-1.

31. Cockrill K, Upadhyay UD, Turan J, Foster DG. The stigma of having an abortion: development of a scale and characteristics of women experiencing abortion stigma. Persp Sex Reprod Health 2013;45:79-88.

32. Shellenberg KM, Hessini L, Levandowski BA. Developing a scale to measure stigmatizing attitudes and beliefs about women who have abortions: Results from Ghana and Zambia. Stigma, research and action. Women Health 2014;54:599-616.

33. Challa S, Manu A, Morhe E, et al. Multiple levels of social influence on adolescent sexual and reproductive health in Ghana. Women Health 2018;58:434-50.

34. Rajapaksa-Hewageegana N, Salway SM, Piercy H, Samarage $\mathrm{S}$. A quantitative exploration of the sociocultural context of teenage pregnancy in Sri Lanka. BMC Preg Childbirth 2014;14:394.

35. Tanner AE, Jelenewicz SM, Ma A, et al. Ambivalent messages: adolescents' perspectives on pregnancy and childbirth. J Adolesc Health. 2013;53:105-11.

36. Creswell JW. Research design: qualitative, quantitative, and mixed methods approaches. 2nd ed. Thousand Oaks, CA: Sage Publications; 2003.

37. Strauss A, Corbin J. Basics of qualitative research: Grounded theory procedures and techniques. Thousand Oaks, CA: Sage Publications; 1990. 